\title{
Breaking the Gender Gap: A Two-part Observational Study of the Gender Disparity Among Korean Academic Emergency Physicians
}

\author{
Mi Jin Lee, Changho Kim \\ Department of Emergency Medicine, Kyungpook National University School of Medicine, Daegu, Korea
}

Objectives: Despite greater access to training positions and the presence of more women in emergency medicine, it has remained a men-dominated field. This study aims to identify the key issues causing the gender gap in Korea and establish measures to overcome them.

Methods: Using the annual statistical reports of the National Emergency Medical Center and data published on the Korean Society of Emergency Medicine website, cases that listed the current status and positions of members in its organization and its committees were analyzed. Secondary analysis was conducted using data from the 2015 Korean Society of Emergency Survey that included physicians' demographics, academic ranking, years of experience, clinical work hours, training and board certification, core faculty status, position, and salaries.

Results: As of September 2019, women account for only $12.7 \%$ of the total number of emergency physicians (EP) in Korea; of 119 chair/ vice-chair academic positions, women represented only 9.2\%. Women EP were more often assistant professors and fellowship-trained, with fewer in core faculty. However, they worked the same numbers of clinical hours as their men counterparts. The median annual salary of women EP was less than that of men EP after adjusting for academic hospital rank, clinical hours, and core faculty status.

Conclusions: A gender gap still exists among Korean EP, and women earn less than men regardless of their rank, clinical hours, or training. Future studies should evaluate more data and develop system-wide practices to eliminate gender disparities.

Key words: Gender identity, Salaries and fringe benefits, Emergency medicine, Academic medical centers, Survey and questionnaires

\section{INTRODUCTION}

Gender parity is fundamental to the progression and prosperity of societies. The appropriate development and use of

Received: June 18, 2020 Accepted: July 20, 2020

Corresponding author: Changho Kim, MD

Department of Emergency Medicine, Kyungpook National University School of Medicine, 680 Gukchaebosang-ro, Jung-gu, Daegu 41944, Korea

E-mail: kch9754130@gmail.com

This is an Open Access article distributed under the terms of the Creative Commons Attribution Non-Commercial License (https://creativecommons.org/licenses/bync/4.0// which permits unrestricted non-commercial use, distribution, and reproduction in any medium, provided the original work is properly cited. women talent, which constitutes half of the world's workforce, is key to the advancement of global economies. Korea has been a low-performing region in this area, according to global studies on gender gaps relation in the workforce $[1,2]$. To zoom in on its healthcare sector, the total number of woman physicians in Korea did increase between 2005 and 2015, with member states reporting that women comprised 50\% or more of their physician workforce. However, the $2018 \mathrm{Glob}$ al Gender Gap Report showed that the number of women in leadership roles in the healthcare sector were still disproportionately low [3,4]. According to official reports from the World Economic Forum and medical research studies, this disparity parallels the glass ceiling phenomenon in academic 
medicine recorded by several studies conducted in the United States [5].

Numerous studies and white papers have reported that most emergency physicians (EP) experience work-related stress, burnout, and wage dissatisfaction as a result of employment mismatch in their field of emergency medicine (EM), but only a few have reported on gender disparity $[6,7]$. Traditionally, EM has been a men-dominated field; despite the influx of women physicians in academic medicine departments, the number of women in chairperson and society leadership positions in EM is very small [8]. Previous studies reported that while women comprised $26 \%$ of all EM faculty positions in the United States, only $6 \%$ were full professors compared to $12 \%$ for all combined medical school departments, and only six women chaired an EM department [9-11].

To our knowledge, no other published data are available on the current gender distribution of EP in Asia, particularly Korea. Although gender in academic medicine has been adopted as a useful parameter in many studies, gender parity has not been sufficiently explored. At the organizational level, no woman has presided the Korean Society of Emergency Medicine (KSEM) in its 30-year history. Therefore, we conducted a two-part analysis of gender differences among Korean EP affiliated with the KSEM to better understand the current situation of women physicians in Korea and their professional challenges.

To this end, we identified problems that caused the gender gap and established measures to overcome them. Additionally, we reviewed the strategies implemented by women emergency physician organizations in developed countries to surmount such obstacles.

\section{METHODS}

\section{Data Sources}

We conducted two-phased, cross-sectional, observational studies of academic EP to better understand the current situation of women physicians, and their professional challenges in Korea. Further, by using the annual statistical report of the National Emergency Medical Center (NEMC), we summarized the overall characteristics of the emergency medical system resources and human resources including board-certified EM physicians [12]. We described the status of the EM resources between December 2015 and September 2019, when the survey and positional assessment were conducted (Supplemental Material 1). The KSEM website was analyzed for cases that listed the current status and clinical positions of physicians within the organization and its committees. We also reviewed the respective websites of the KSEM, its committees, and relevant academic societies affiliated with the KSEM, to understand woman participation in their boards of directors $[13,14]$. We used the KSEM's annual reports on residency training, followed by a review of program websites, to procure data on all $89 \mathrm{EM}$ residency teaching hospitals that were accredited by the educational committee of the KSEM.

\section{Korean Emergency Physician Survey}

Since 2010, the KSEM survey has been conducted periodically every five years in Korea. The 2015 survey included physician demographics (gender, age, marital status); year of medical school and residency completion; academic ranking; years of experience; training and board certifications; number of publication articles; core faculty status; the overall weekly work hours (clinical+education+researching+administration activity); salary, and stress and burnout issues $[15,16]$. This particular survey was based on the 2014 Longitudinal Study of Emergency Physicians, a five-year survey performed by the American Academy of Emergency Medicine [17-20].

The KSEM survey was conducted over three months between August 1, 2015 and October 31, 2015. The questionnaire was available on the KSEM website and could be submitted online; it was also emailed to 1418 EP [16]. A total of 483 responses were received. Respondents either self-identified as women or did not disclose gender; the response rate for this question was $34.1 \%$. All participants consented to the purpose and intent of the survey at the start of the questionnaire. Where respondents left one or two items unanswered, we treated these instances as missing values for the analysis. In total, data from 437 respondents were included in the final analysis. The survey organizers then took two years to verify the quality control and remove any personally identifiable information from the data. In October 2017, the data were released and made available to researchers and members of the KSEM society.

\section{Measures and Endpoints}

The primary outcome was gender composition of leadership positions (e.g., chairperson, faculty), determined using data from the KSEM annual reports and websites of KSEM-related societies. The secondary outcomes were gender gaps in academic positions, annual work hours, monthly salary, publica- 
tions, and quality of life scores, derived from the 2015 KSEM Emergency Physician Survey dataset.

\section{Statistical Analysis}

Data were analyzed using SPSS version 25 (IBM Corp., Armonk, NY, USA) and MedCalc version 17 (MedCalc Software, Mariakerke, Belgium). Categorical variables were presented as frequency and percentage, whereas continuous variables were presented as mean \pm standard deviation (SD), or as median and interquartile range (IQR; 25th-75th percentile). Chi-squared or Fisher's exact tests were used to compare the categorical variables. The normality of the variables was determined using the Shapiro-Wilk test. Normally distributed data were expressed with mean and SD, and median and IQRs were used for nonnormally distributed data. A $t$-test or one-way analysis of variance and Mann-Whitney U-test were used to compare continuous variables. Using two-way analysis of variance, we assessed salary gaps among the positional ranks for differences in the importance attributed to gender factors. All tests were two-tailed, and a $p$-value of $<0.05$ was considered statistically significant.

\section{Ethics Statement}

Both surveys were reviewed and approved by the Institutional Review Board of Kyungpook National University Chilgok Hospital (KNUCH 2017-09-017, 2020-01-041).

\section{RESULTS}

\section{Overall Characteristics of Emergency Physicians and Related Resources}

Based on the KSEM data for registered there were 1609 men clinicians and 234 women clinicians in Korea in September 2019; women made up $12.7 \%$ of the total number (Figure 1). The mean age of women EP was 39.6 years. Supplemental Material 1 summarizes the main characteristics of the national emergency medical system resources and board-certified EM physicians, derived from the annual NEMC statistical reports for December 2015 and September 2019.

\section{Women Emergency Physicians at Leadership Positions \\ Positions held in KSEM-related academic societies}

At the organizational level, no woman has presided over the KSEM in its 30-year history. As of September 2019, the board of officers and other leadership committees-which determine the strategic direction of the KSEM — comprised solely of men. Among the 24 KSEM associations and societies, only one is chaired by a woman. Of 20 editorial board members of the official journal of the KSEM, only four are women. This underrepresentation is also observed in the different affiliated societies, wherein men primarily constitute the boards of leadership offices. Of 119 chair/vice-chair academic positions, only $11.0 \%$ or $9.2 \%$ were held by women. Figure 2 breaks down the

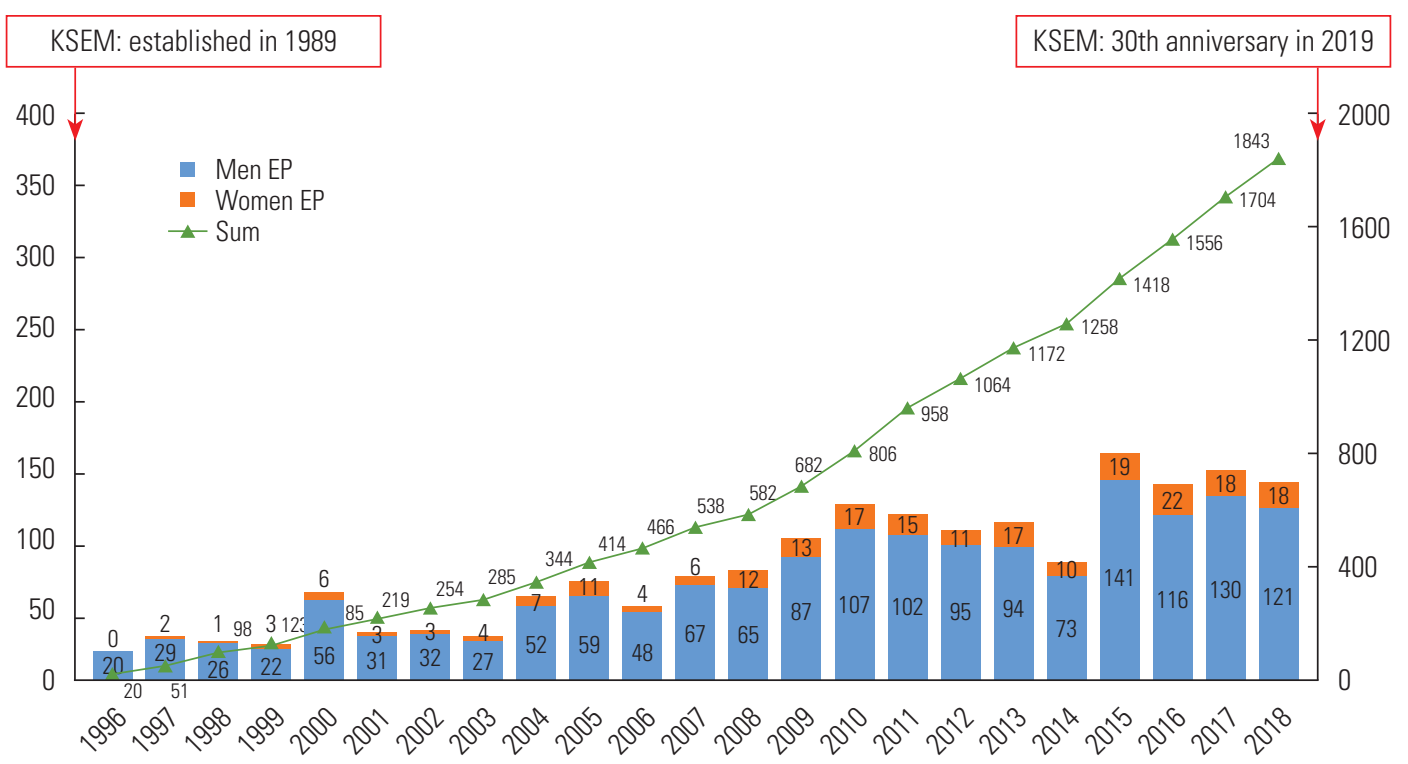

Figure 1. Annual census of board-certified emergency physicians (EP) by gender. KSEM, Korean Society of Emergency Medicine. 
KSEM Past presidents (17)

President, Vice presidents, chairman, Auditor (5)

Board of directors, Committee Chairs (24)

KSEM Affiliated Associations, President (3)

Korean Society of Pediatric Emergency Medicine, Board of directors (22)

Korean Society of Clinical Toxicology, Board of directors (16)

Society of Emergency \& Critical Care Imaging, Board of directors (12)

Affiliated Academic Society, President (10)

Regional Emergency Society, President (10)

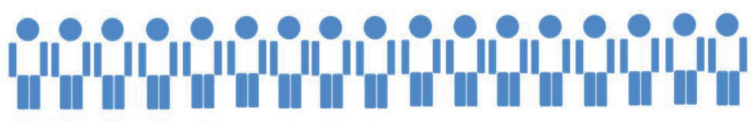

|| ||

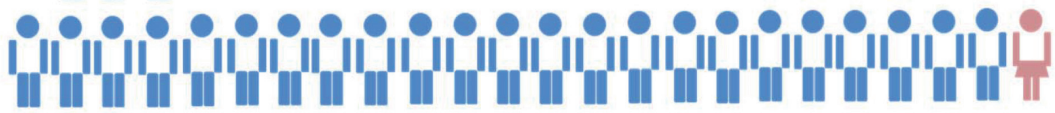
(1)

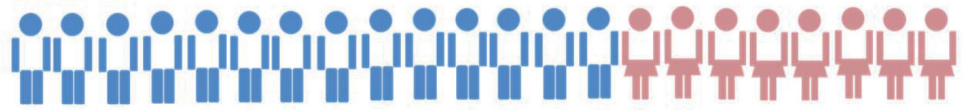
|| m-110

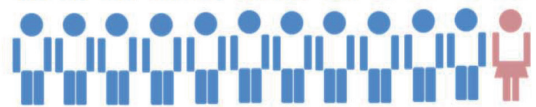
10 1.

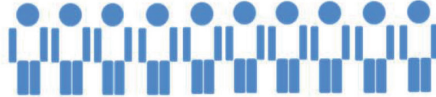

Figure 2. Women representation in the Korean Society of Emergency Medicine (KSEM) and affiliated societies. Of 119 chair/vicechair academic positions, only $9.2 \%$ of those were held by women (11/119). Data obtained from their respective websites and the KSEM website on September 30, 2019.

absolute numbers of women holding leadership positions across the academic societies.

\section{Positions held in EM teaching hospitals}

We analyzed data from all 89 EM residency teaching hospitals in Korea: training hospitals accredited by the Joint Residency Advisory and Accreditation Committee and certified by the Korean Hospital Association. Of these, only four or $4.5 \%$ were chaired by a woman in September 2019.

\section{Survey Characteristics of Emergency Physicians Overall characteristics of respondents}

The average age of the respondents was 37.0 years for women and 40.0 years for men (Table 1). Most women were married (52.0\%) and did not have any children (58.0\%). Women EP worked mainly at the academic hospital level or in emergency medical centers (regional and local) whereas $34.0 \%$ of men worked in private clinics or emergency facilities. In the faculty rankings, there were fewer women in the overall number of professionals, and more men advanced to pay doctor than women. Women were more likely than men to become assis- tant professors (31.5\% of all woman physicians vs. $18.0 \%$ of all man physicians) and to receive fellowship training (18.5\% of all woman physicians vs. $6.0 \%$ of all man physicians). Women also had a significantly lower expected retirement age than men (55 years and 60 years, respectively; $p<0.001$ ).

\section{Clinical activity (annual work hours) and salary gaps}

Based on the 2015 KSEM survey, the overall work hours over a four-week period were similar for man and woman EP (both 184.0 hours [IQR, 160.0 to 224.0$]$, respectively; $p=0.925$ ). In the number of night shifts worked per month, there was a statistically difference, with 6.0 for women and 7.0 for men $(p=0.010)$. In comparison, on average, women earned 30000 US dollar (USD) less annually than their men counterparts. The salary differences between man and woman EP are shown in Table 1 . Salaries were divided into four grades according to the amount of wages. For salary grades higher than 12000 USD per month, there was a statistically significant difference between men and women (37.0\% and $13.0 \%$, respectively). Table 1 also breaks down the clinical activity as well as research and education activity. 
Table 1. General characteristics and work-related differences of EP according to gender

\begin{tabular}{|c|c|c|c|c|}
\hline Characteristics & Overall & Women EP & Men EP & $p$-value \\
\hline Total & $437(100)$ & $54(12.4)$ & $383(87.6)$ & $<0.001$ \\
\hline Age (y) & $39.0[37.0,44.0]$ & $37.0[35.0,39.0]$ & $40.0[37.0,44.0]$ & \\
\hline Years since residency & $7.0[4.0,11.0]$ & $6.0[3.0,9.0]$ & $7.0[4.0,11.0]$ & 0.124 \\
\hline Faculty rank & & & & $<0.001$ \\
\hline Professor & $27(6.2)$ & $1(1.9)$ & $26(6.8)$ & \\
\hline Associate professor & $46(10.5)$ & $7(13.0)$ & $39(10.2)$ & \\
\hline Assistant professor & $86(19.7)$ & $17(31.5)$ & $69(18.0)$ & \\
\hline Instructor, fellowship & $33(7.6)$ & $10(18.5)$ & $23(6.0)$ & \\
\hline Clinical physician or hospitalist & $6(1.4)$ & $0(0.0)$ & $6(1.6)$ & \\
\hline Pay-doctor, general practitioner & $201(46.0)$ & 19 (35.2) & $182(47.5)$ & \\
\hline Full time faculty & $159(36.4)$ & $25(43.3)$ & $135(35.0)$ & 0.106 \\
\hline Type of hospital & & & & 0.038 \\
\hline Academic hospital/training & $165(37.8)$ & $25(46.3)$ & $140(36.6)$ & \\
\hline Non-academic hospital & $234(53.5)$ & $29(53.7)$ & $205(53.5)$ & \\
\hline Military services, obligation & $38(8.7)$ & $0(0.0)$ & $38(9.9)$ & \\
\hline Level of EMC & & & & 0.024 \\
\hline Level 1 (regional EMC) & $46(10.5)$ & $11(20.4)$ & $35(9.1)$ & \\
\hline Level 2 (local EMC) & $244(55.8)$ & $26(50.0)$ & $218(56.9)$ & \\
\hline Level 3 (emergency facility) & $105(24.0)$ & $9(16.7)$ & $96(25.1)$ & \\
\hline Other facilities & $42(9.6)$ & $8(14.8)$ & $34(8.9)$ & \\
\hline \multicolumn{5}{|l|}{ Clinical activity } \\
\hline Monthly worked hours, total & $184[160.0,224.0]$ & $184[164.0,224.0]$ & $184[160.0,224.0]$ & 0.925 \\
\hline \multicolumn{5}{|l|}{ Monthly working schedule } \\
\hline Work/duty days & $12.0[10.0,17.5]$ & $12.0[8.0,20.0]$ & $12.0[10.0,16.0]$ & 0.395 \\
\hline Night duty/night shift & $7.0[5.0,8.0]$ & $6.0[5.0,7.0]$ & $7.0[5.0,8.0]$ & 0.010 \\
\hline \multicolumn{5}{|l|}{ Research and education activity } \\
\hline Weekly hours spent on education & $0.0[0.0,4.0]$ & $2.0[0.0,3.0]$ & $0.0[0.0,4.0]$ & 0.055 \\
\hline Weekly hours spent on research & $0.0[0.0,5.0]$ & $2.0[0.0,8.0]$ & $0.0[0.0,4.0)$ & 0.005 \\
\hline Weekly hours for administration & $0.0[0.0,4.0]$ & $2.2[0.0,4.0]$ & $3.2[0.0,6.5]$ & 0.113 \\
\hline Publication articles, total & $2.0[0.0,6.0]$ & $2.0[0.5,7.0]$ & $1.0[0.0,6.0]$ & 0.150 \\
\hline \multicolumn{5}{|l|}{ Salary (USD) } \\
\hline Annual salary in 2015 & $113750[81250,146$ 250] & $81250[70416,113$ 750] & $114700[83$ 000, 149 450] & $<0.001$ \\
\hline Grading of monthly salary in 2015 & & & & 0.014 \\
\hline Not surveyed & $37(8.5)$ & $6(11.1)$ & $31(8.1)$ & \\
\hline$\leq 7000$ & $94(21.5)$ & 16 (29.6) & $78(20.4)$ & \\
\hline 7000-11999 & $157(35.9)$ & $25(46.3)$ & $132(34.5)$ & \\
\hline $12000-16999$ & $142(32.5)$ & $7(13.0)$ & $135(35.2)$ & \\
\hline$\geq 17000$ & $7(1.6)$ & $0(0.0)$ & $7(1.8)$ & \\
\hline Expected retirement age & $60.0[55.0,65.0]$ & $55.0[50.0,60.0]$ & $60.0[55.0,65.0]$ & $<0.001$ \\
\hline
\end{tabular}

Values are presented as number (\%) or median [interquartile range]. $E P$, emergency physician; EMC, emergency medical center; USD, US dollar.

${ }^{1}$ Mann-Whitney U-tests and chi-square comparisons where appropriate.

Table 2 compares age, monthly work hours, annual salary (USD), and monthly night shifts between men and women EP in academic versus non-academic hospitals. Unadjusted sala- ries were found to be statistically significant between the genders in academic hospitals $(p=0.02)$ and non-academic hospitals $(p<0.001)$. 
Table 2. Salary and hours worked according to gender and type of hospital

\begin{tabular}{|c|c|c|c|c|c|c|}
\hline \multirow{2}{*}{ Characteristics } & \multicolumn{3}{|c|}{ Academic hospital } & \multicolumn{3}{|c|}{ Non-academic hospital } \\
\hline & Men EP & Women EP & $p$-value ${ }^{1}$ & Men EP & Women EP & $p$-value ${ }^{1}$ \\
\hline Age (y) & $43.5 \pm 5.6$ & $39.0 \pm 2.4$ & $<0.001$ & $40.1 \pm 4.9$ & $36.3 \pm 3.5$ & $<0.001$ \\
\hline Hours worked, monthly & $15.8 \pm 5.8$ & $15.4 \pm 5.3$ & 0.786 & $12.4 \pm 3.9$ & $11.2 \pm 6.2$ & 0.368 \\
\hline Annual salary (median, US dollar) & 91016 & 81250 & 0.002 & 137901 & 99883 & $<0.001$ \\
\hline Night shift, monthly & $4.8 \pm 2.7$ & $5.3 \pm 2.2$ & 0.369 & $7.5 \pm 2.8$ & $5.9 \pm 2.1$ & 0.006 \\
\hline
\end{tabular}

Values are presented as mean \pm standard deviation.

EP, emergency physician.

${ }^{1}$ Mann-Whitney U-tests and two-way analysis of variance where appropriate.

\section{DISCUSSION}

The first part of our study revealed that the most influential, policy-determining positions in the KSEM are almost exclusively occupied by men, and that there remains a gross underrepresentation of women at leadership positions. Moreover, woman EP are less likely to be full-time professors, and more likely to experience salary gaps compared to their men counterparts.

Discrimination against women in the workforce still exists in many aspects of the Korean society due to its longstanding beliefs in Confucianism. To qualify, the number of women EP in Korea is steadily increasing, and there are currently 234 of them in the country. However, increases in the number of women physicians, often called the "feminization of medicine," have not always been accompanied by an increase in their power. We examined women physicians' gendered experiences through the lenses of cultural and social practices in Korea to understand the complexity of women's career development in academic medicine. As mentioned, the Korean culture is characterized by collectivism, patriarchy, and a strong work ethic. The cultural emphasis on men superiority compels women to support men and accept that women's failures are due to their own incompetence rather than inequality [21]. Even now, there are little or no Asian studies investigating problems related to the career advancement of women EP. While women EP in Korea are fully aware of and sympathetic toward these issues, but they have been unable to undertake practical measures to improve the situation.

This phenomenon is referred to as the "glass ceiling," a metaphor used to denote the decreased likelihood of women to be promoted to higher hierarchical positions despite equal seniority and productivity. It has been postulated that the lack of progression in women careers has resulted from men-oriented organizational cultures, with women excluded from the necessary networking and mentoring required for professional ad- vancement. Numerous studies have revealed that women are as eager and qualified as men to assume leadership positions, being equally good at leadership tasks. However, of 113 chair/ vice-chair positions in the United States, only 15\% were women EP [20]. Additionally, women were more likely to receive fellowship training than their men counterparts (37\% of women compared to $31 \%$ of men); they also earned less than their men counterparts (19 000 USD) although they worked similar numbers of clinical hours [20].

As of 2019, women EP accounted for $12 \%$ of the total number of EP in Korea. However, our study reveals that men clinicians occupy most of the influential and policy-making positions in the KSEM. In the faculty rankings, the number of fulltime tenured women professionals was one (1.9\%), while that of men was 26 (6.8\%). Further, women EP were expected to retire younger at 55 years due to issues such as childcare and physical health problems. When salary was divided into four grades based on wages, we observed more men in the salary bracket of $\geq 17000$ USD per month; when salary was classified based on occupation, we observed a larger gender gap in salary for the pay-doctor position. As a result, there was a statistical significance in the difference in salaries between men EP and women EP; this difference seems to be affected by the number of night shift ( 6.0 for women and 7.0 for men, $p=0.010$ ), replacement of certified length for men EP to work in military service, and the higher salary gap in the pay-doctor group.

Concerning academic ranking, only one third of academic faculty members are women, and these physicians face significant gender-based disparities in representation and academic ranking; this issue is present in several medical specialties. Most significantly, Bennett et al. [19] reported that only $20.4 \%$ of women EP were associate or full-time professors $(14.6 \%$ and $5.8 \%$, respectively), an imbalance that the researchers suggested has contributed to numerous other gender disparities in $E M$, including differences in compensation, grant funding, ad- 
ministrative roles, and leadership positions. Moreover, these women EP were younger and had completed their residencies more recently than their men counterparts. In fact, although many medical specialties have witnessed increases in woman residents over the past decade [4,5,22], EM has not (36\% women residents in 2005 vs. $37 \%$ in 2015) [19,23]. In the present study, only $14.8 \%$ of women EP in Korea were found to be associate or full professors (13.0\% and $1.9 \%$, respectively). For this, we suggest that future studies include targeted strategies for the recruitment and retention of women residents to increase women faculty. There remains an obvious unmet need to encourage and promote diversity, inclusion, and equal advancement of genders in the field of academic EM.

Another key issue is the lack of same-gender mentors and role models for women in academic areas [24]. Searching "glass ceiling" in PubMed, we found 267 articles that discussed discrimination against women in various medical fields, with recommended solutions to overcome the leadership gap. Korea could benchmark against and adopt best practices from several societies (e.g., European Association of Neurosurgical Societies, American Association of Women Emergency Physicians) [4,24]. It provides a broad-based network of support, guidance, and education in personal and professional leadership skills, particularly for women physicians, residents, and medical students.

The Taskforce for Women in Academic Emergency Medicine in the United States has also been pivotal in guiding policymaking and implementing strategies to foster recruitment, retention, and career advancement of women EP [25]. However, a sister society or taskforce does not exist for EM in Asia. Korean women physicians believe that such a committee should be created within the KSEM. We have, therefore, submitted a proposal to the board of directors for the creation of a committee for women in KSEM. The goal of the committee would be to counteract the glass ceiling effect in an institutionalized manner: to identify the issues and obstacles women physician face across Asia, create a mentoring platform to partner young women physicians with senior women consultants at leadership positions to enhance their motivation in their own professional journeys, and provide strategies and solutions for the issues identified. On the basis of other women's experiences, we suggest this step-by-step method to enhance leadership opportunities for women physicians and overcome gender disparity in Korea. First, we publish an annual report or white paper on the current status of gender disparity among Korean EP. Second, we emphasize the role and political voice of wom- en in the society, supported by basic data. Third, we review the strategies implemented by organizations supporting women EP in developed countries. Finally, women physicians can create one such organization together by strengthening linkages and mentoring future leaders.

There are several limitations to our research. First, our study was subjected to selection bias, since not all Korean EP are included in the KSEM mailing list and not all from that list responded to the survey. Furthermore, our response rate of $34.1 \%$ is relatively low. It is possible that departments that participated were more confident in their hiring, salary conferral, and promotion practices, or had the data readily available owing to prior audits of these processes, thus creating a picture that underestimates existing gender disparities. As several EP did not respond, responses could also have skewed towards academic hospitals or geographic regions. Second, our study participants displayed a variety of demographic characteristics; however, most survey respondents were relatively young, with a mean age of 36 years. This could also have skewed the results, with an under-representation of more senior emergency physicians. Therefore, the generalization of the findings will not extend to other population. To further understand this subject, we should acquire more data regarding women participation in EM and perceptions of career development for women EP.

In conclusion, some gender gaps still reveal in their academic rank and salaries among EP. Our survey findings offer a glimpse into the obstacles encountered by women in this field. We hope that our study will open more dialogues on this important issue and that the proposal submitted to the healthcare policy will help create more equitable opportunities among EP.

\section{SUPPLEMENTAL MATERIALS}

Supplemental material is available at https://doi.org/10.3961/ jpmph.20.286.

\section{CONFLICT OF INTEREST}

The authors have no conflicts of interest associated with the material presented in this paper.

\section{FUNDING}

None. 


\section{ACKNOWLEDGEMENTS}

None.

\section{AUTHOR CONTRIBUTIONS}

Conceptualization: MJL, CK. Data curation: MJL. Formal analysis: MJL, CK. Funding acquisition: None. Methodology: CK. Project administration: MJL, CK. Visualization: MJL, CK. Writing original draft: MJL, CK. Writing - review \& editing: MJL, CK.

\section{ORCID}

Mi Jin Lee https://orcid.org/0000-0002-3773-8047

Changho Kim https://orcid.org/0000-0002-7552-8200

\section{REFERENCES}

1. Choe SA, Cho SI, Kim H. Gender gap matters in maternal mortality in low and lower-middle-income countries: a study of the global Gender Gap Index. Glob Public Health 2017;12(9): 1065-1076.

2. World Economic Forum. The global gender gap report 2017 [cited 2019 Sep 30]. Available from: https://www.weforum. org/reports/the-global-gender-gap-report-2017.

3. Kang SK, Kaplan S. Working toward gender diversity and inclusion in medicine: myths and solutions. Lancet 2019;393 (10171):579-586.

4. Wolfert C, Rohde V, Mielke D, Hernández-Durán S. Female neurosurgeons in Europe-on a prevailing glass ceiling. World Neurosurg 2019;129:460-466.

5. Zhuge Y, Kaufman J, Simeone DM, Chen H, Velazquez OC. Is there still a glass ceiling for women in academic surgery? Ann Surg 2011;253(4):637-643.

6. Lee YK, Lee CC, Chen CC, Wong CH, Su YC. High risk of 'failure' among emergency physicians compared with other specialists: a nationwide cohort study. Emerg Med J 2013;30(8):620622.

7. James T. Women in Academic Emergency Medicine/Diversity Interest Group position statement. Acad Emerg Med 2000; 7(9):1032-1035.

8. Cydulka RK, D'Onofrio G, Schneider S, Emerman CL, Sullivan LM. Women in academic emergency medicine. Acad Emerg Med 2000;7(9):999-1007.

9. Cheng D, Promes S, Clem K, Shah A, Pietrobon R. Chairperson and faculty gender in academic emergency medicine departments. Acad Emerg Med 2006;13(8):904-906.

10. Bickel J, Wara D, Atkinson BF, Cohen LS, Dunn M, Hostler S, et al. Increasing women's leadership in academic medicine: report of the AAMC Project Implementation Committee. Acad Med 2002;77(10):1043-1061.

11. Morton MJ, Sonnad SS. Women on professional society and journal editorial boards. J Natl Med Assoc 2007;99(7):764-771.

12. National Emergency Medical Center. 2018 Yearbook of emergency medical statistics [cited 2019 Oct 30]. Available from: https://www.e-gen.or.kr/nemc/statistics_annual_report.do (Korean).

13. Korean Society of Clinical Toxicology. Introduction and guidance of the Korean Society of Clinical Toxicology. [cited 2019 Oct 30]. Available from: https://ksclintox.jams.or.kr/co/com/ EgovMenu.kci?s_url=/sj/config/soceHomePgConf/guide/ sjGuidNewView.kci?guidSeq $=000000000003 \&$ s_Menuld $=$ MENU-000000000011000\&s_tabld $=1 \&$ accnld $=$ AC00000000 (Korean).

14. Korean Society of Emergency Medicine. KSEM leadership [cited 2019 Oct 30]. Available from: http://www.emergency.or.kr/ English.

15. Lee HM, Cho KH, Yang HJ, Kim IB, Lee KJ, Han SB, et al. 2015 Korean Society of Emergency Physician Survey (KEPS): major changes from 2010 to 2015. J Korean Soc Emerg Med 2016; 27(5 Suppl):25-40 (Korean).

16. Shin J, Kim YJ, Kim JK, Lee DE, Moon S, Choe JY, et al. Probability of early retirement among emergency physicians. J Prev Med Public Health 2018;51(3):154-162.

17. Smith-Coggins R, Broderick KB, Marco CA. Night shifts in emergency medicine: the American board of emergency medicine longitudinal study of emergency physicians. J Emerg Med 2014;47(3):372-378.

18. Marco CA, Broderick K, Smith-Coggins R, Goyal DG, Joldersma $\mathrm{KB}$, Coombs AB. Health and wellness among emergency physicians: results of the 2014 ABEM longitudinal study. Am J Emerg Med 2016;34(8):1715-1716.

19. Bennett CL, Raja AS, Kapoor N, Kass D, Blumenthal DM, Gross $\mathrm{N}$, et al. Gender differences in faculty rank among academic emergency physicians in the United States. Acad Emerg Med 2019;26(3):281-285.

20. Madsen TE, Linden JA, Rounds K, Hsieh YH, Lopez BL, Boatright $D$, et al. Current status of gender and racial/ethnic disparities among academic emergency medicine physicians. Acad Emerg Med 2017;24(10):1182-1192. 
21. Han H, Kim Y, Kim S, Cho Y, Chae C. Looking into the labyrinth of gender inequality: women physicians in academic medicine. Med Educ 2018;52(10):1083-1095.

22. Mueller C, Wright R, Girod S. The publication gender gap in US academic surgery. BMC Surg 2017;17(1):16.

23. Dayal A, O'Connor DM, Qadri U, Arora VM. Comparison of male vs female resident milestone evaluations by faculty during emergency medicine residency training. JAMA Intern Med 2017;177(5):651-657.
24. Welch JL, Jimenez HL, Walthall J, Allen SE. The women in emergency medicine mentoring program: an innovative approach to mentoring. J Grad Med Educ 2012;4(3):362-366.

25. Kuhn GJ, Abbuhl SB, Clem KJ; Society for Academic Emergency Medicine (SAEM) Taskforce for Women in Academic Emergency Medicine. Recommendations from the Society for Academic Emergency Medicine (SAEM) Taskforce on women in academic emergency medicine. Acad Emerg Med 2008;15(8): 762-767. 